\title{
Extranodal follicular dendritic cell sarcoma in mesentery: A case report
}

\author{
ZHONGQI LI $^{1}$, KETAO JIN ${ }^{1,4}$, XIONGFEI YU ${ }^{1}$, XIAODONG TENG ${ }^{2}$, \\ HUA ZHOU $^{3}$, YANLI WANG ${ }^{2}$, LISONG TENG ${ }^{1}$ and FEILIN CAO ${ }^{5}$ \\ Departments of ${ }^{1}$ Surgical Oncology, and ${ }^{2}$ Pathology; ${ }^{3}$ Imaging Center, First Affiliated Hospital, \\ College of Medicine, Zhejiang University, Hangzhou; ${ }^{4}$ Department of Surgery, \\ Affiliated Zhuji Hospital, Wenzhou Medical College, Zhuji; ${ }^{5}$ Department of Surgical Oncology, \\ Taizhou Hospital, Wenzhou Medical College, Taizhou, Zhejiang, P.R. China
}

Received February 9, 2011; Accepted April 27, 2011

DOI: $10.3892 / \mathrm{ol} .2011 .296$

\begin{abstract}
Extranodal follicular dendritic cell (FDC) sarcomas are not a common phenomenon. Due to the scarcity of the identified cases reported in the literature, FDC is probably under-recognized and commonly misdiagnosed. The diagnosis of FDC sarcomas is based on node-based spindle cell lesions, and the expression of CD21, CD35 and clusterin. The most commonly involved extranodal sites include the oral cavity, tonsil, gastrointestinal tract and liver. With the aid of immunohistochemical analysis and the two most reliable FDC markers, CD21 and CD35, the diagnostic accuracy has improved. When FDC sarcoma is suspected histologically, immunohistochemical stains for FDC differentiation should be performed to avoid potential misdiagnosis. This case report concerns the evaluation of a 43-year-old male Chinese patient with a large extranodal FDC sarcoma $(20 \times 18 \times 9 \mathrm{~cm})$ in the mesentery with elevated serum CA125 (76.9 U/ml). The diagnosis and treatment of this disease are also discussed.
\end{abstract}

\section{Introduction}

Follicular dendritic cell (FDC) sarcoma, first reported in 1986, is a rare neoplastic proliferation of FDCs (1). It originates from follicular dendritic cells of the lymphoid tissue that affect mainly lymph nodes. The diagnosis of FDC sarcomas is based on node-based spindle cell lesions, and the expression of CD21, CD35 and clusterin. FDC sarcoma with an extranodal

Correspondence to: Dr Lisong Teng, Department of Surgical Oncology, First Affiliated Hospital, College of Medicine, Zhejiang University, 79 Qingchun Road, Hangzhou, Zhejiang 310003, P.R. China

E-mail: 1steng@hos.zju.edu.cn or jinketao2001@yahoo.com.cn

Dr Feilin Cao, Department of Surgical Oncology, Taizhou Hospital, Wenzhou Medical College, 150 Ximen Road, Taizhou, Zhejiang 317000, P.R. China

E-mail:dr.caofeilin@yahoo.com.cn

Key words: dendritic cell sarcoma, extranodal, follicular, mesentery origin is extremely rare. The most common sites of extranodal FDC sarcoma are the oral cavity, tonsil, gastrointestinal tract and liver (2). The clinical and pathological characteristics of extranodal FDC sarcoma remain under-recognized, mainly due to limited reported cases in the literature. This case report focuses on one more case of this rare tumor occurring in the mesentery, and its diagnosis and treatment are discussed.

\section{Case report}

A 43-year-old Chinese male presenting with an upper abdominal painless mass for approximately 3 months was admitted to our hospital. A physical examination revealed a firm and palpable tumor, predominantly in the right superior abdominal quadrant. There was no evidence of regional lymph node enlargement. The laboratory examination revealed that all parameters were within normal levels, with the exception of serum CA125, which was elevated to $76.9 \mathrm{U} / \mathrm{ml}$. The patient had a 20 -year history of tobacco intake of one packet per day. An ultrasound scan revealed a number of hypoechoic or anechoic placeholders in the abdomen. The axial contrast-enhanced computed tomographic (CT) scan showed a large multilobulated intra-abdominal mass, exhibiting heterogeneous enhancement and marked necrosis (Fig. 1A). The coronal reconstruction $\mathrm{CT}$ image revealed the size, contour and location of the tumor, and indicated no obvious abdominal organ involved (Fig. 1B). Fine-needle aspiration cytology showed a low-grade soft tissue tumor (data not shown).

Intraoperative exploration revealed a large intra-abdominal mass $(20 \times 18 \times 9 \mathrm{~cm})$ located from the transverse colon to the aortic bifurcation level. The pancreas, kidney and intestine nearby were compressed to some extent by the mass. The mass appeared to be well-encapsulated. A radical resection of the tumor was successfully performed. Gross examination of the resected tumor revealed that it was an integration of several well-circumscribed, multilobulated and focally hemorrhagic masses surrounded by a complete fibrous capsule (Fig. 2A). The freshly cut surface of the mass was heterogeneous in color, from light gray to brown-yellow, and exhibited focal irregular hemorrhagic-cystic changes and necrotic areas (Fig. 2B). A microscopic examination of the solid tumor revealed that 

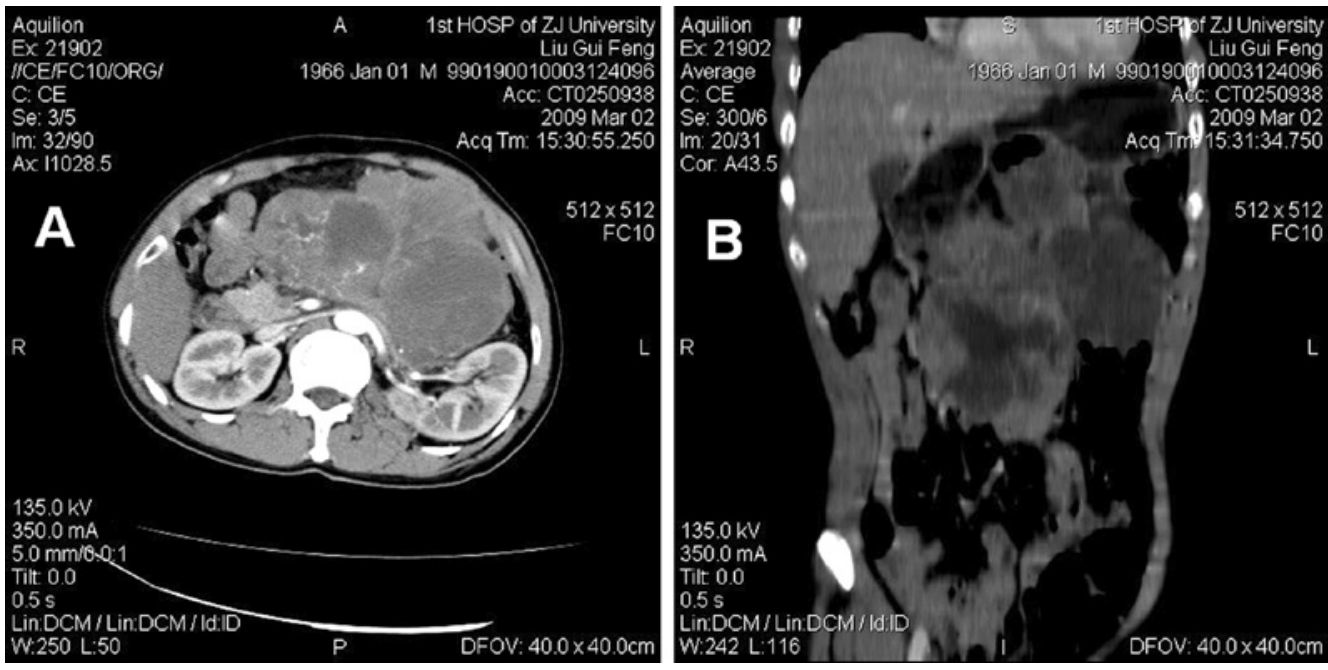

Figure 1. Radiological features of extranodal follicular dendritic cell (FDC) sarcoma revealed by a computed tomographic (CT) scan. (A) Axial contrastenhanced CT scan revealed a large multilobulated intra-abdominal mass, exhibiting heterogeneous enhancement and marked necrosis. (B) Coronal reconstruction CT image showed the size, contour and location of the tumor, and indicated no obvious abdominal organ involved.
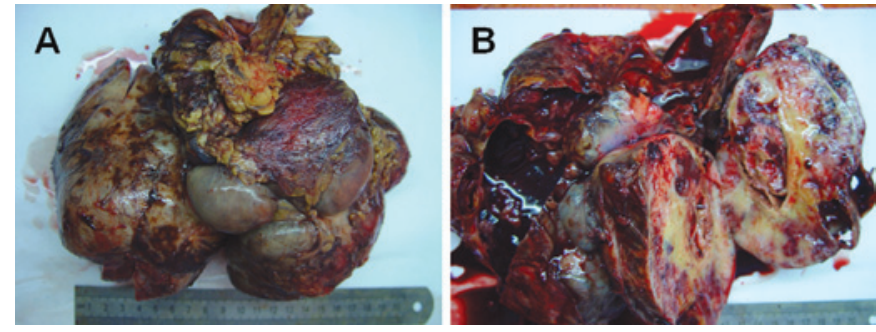

Figure 2. Macroscopic view of the resected tumor. (A) The tumor was an integration of several well-circumscribed, multilobulated, gray-to-yellow and focally hemorrhagic masses. (B) The freshly cut surface of the mass was heterogeneous in color, from light gray to brown-yellow, and exhibited focal irregular hemorrhagic-cystic changes and necrotic areas. The tumor was surrounded by a complete fibrous capsule.

the ovoid to spindle cells were arranged predominantly in fascicles, storiform and whorls, and formed vague nodules (Fig. 3A and B). The individual neoplastic cells exhibited indistinct cell borders resulting in a syncytial appearance and a moderate amount of eosinophilic cytoplasm (Fig. 3C). The nuclei were oval with distinct nucleoli and thin smooth nuclear membranes. Binucleated and multinucleated tumor cells were occasionally observed. The tumor was typically infiltrated by small lymphocytes (Fig. 3D). The admixed small lymphocytes were mixed with $\mathrm{B}$ and $\mathrm{T}$ cells. Necrosis and hemorrhagiccystic changes were present and filled with necrotic debris. Immunohistochemical staining revealed that the tumor was strongly positive for CD21 and CD23 (Fig. 4), and weakly positive for vimentin (data not shown). No additional adjuvant chemotherapy was performed. After 18 months of regular follow-up the patient is asymptomatic.

\section{Discussion}

FDCs are found in primary and secondary lymphoid follicles and play an essential role in antigen presentation for the B-cell compartment, as well as regulation of the germinal
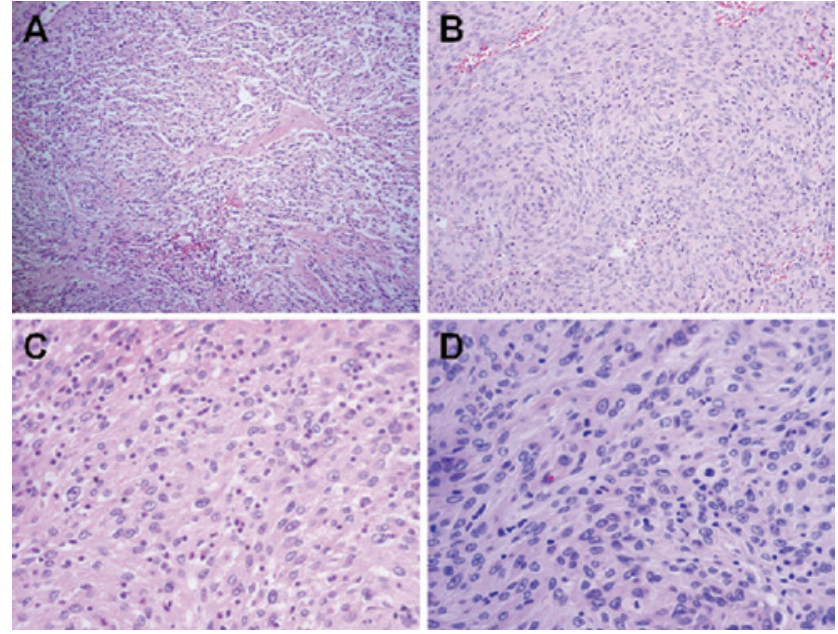

Figure 3. Microscopic examination of the solid component of the mass using H\&E staining. Bundles of ovoid to spindle cells with pinkish cytoplasm were arranged predominantly in fascicles, storiform and whorls, and formed vague nodules (original magnification: A, x100; B, x200). Individual neoplastic cells showed indistinct cell borders resulting in a syncytial appearance and a moderate amount of eosinophilic cytoplasm $(C, x 400)$. The tumor was typically infiltrated by small lymphocytes (D, x400).
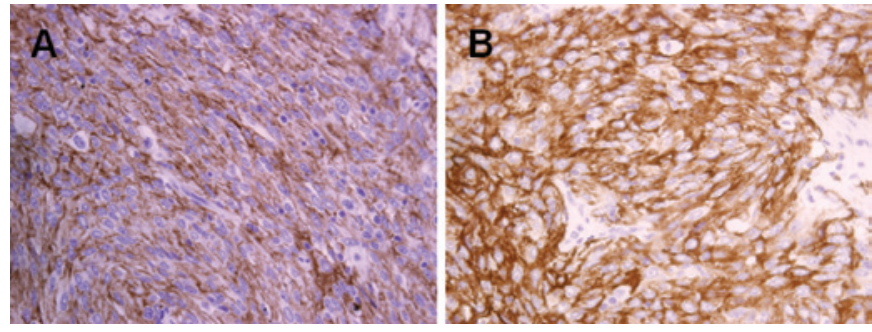

Figure 4. Immunohistochemical staining revealed positive CD21 (original magnification: A, x400) and CD23 (B, x400) expression.

center reaction. The exact origin of FDCs remains unclear and hematopoietic lineage origin or stromal-cell derivation has been proposed. Proliferation of FDCs leads to benign 
reactive lesions or generates neoplastic conditions. It was not until 1986 that the FDC tumor was first characterized by Monda et al (1). Since then, a number of studies have been reported, expanding the clinical and morphologic spectrum.

Extranodal FDC sarcoma was first reported by Chan et al in 1994 (3). Since then, the spectrum of FDC sarcoma in extranodal sites has greatly expanded to include locations throughout the body, such as head and neck, liver, spleen, gastrointestinal tract, soft tissue, skin, lung and breast (3-21). However, due to limited reported cases in the literature, the clinical and pathological characteristics of extranodal FDC sarcoma remained under-recognized. Almost one-third of cases were misdiagnosed at initial evaluation (3,5-26). The main cause of misdiagnosis is that it is impossible to initially consider a poorly differentiated tumor in the extranodal site to be FDC sarcoma when it is first encountered. Another cause is that FDC markers are not routinely used for detecting FDC sarcoma in the extranodal sites.

The diagnosis of FDC sarcoma is established based on the findings of morphology and immunohistochemistry (7). FDC sarcoma has distinct pathological characteristics that facilitate an accurate diagnosis. The histological features of FDC sarcoma tend to be stereotypical (3). It is composed of spindle or oval cells arranged in sheets, nets and fascicles, and focally exhibiting a storiform or whorled growth pattern. Positive immunohistochemical staining of CD21, CD35 and CD23 was particularly useful for the final diagnosis of FDC sarcoma. In the present case, microscopic findings were consistent with those of the studies mentioned above and a diagnosis of FDC sarcoma resulted.

In the present case, the laboratory examination indicated that serum CA125 was elevated to $76.9 \mathrm{U} / \mathrm{ml}$ pre-operatively and decreased to a normal level of 5.5-5.7 U/ml post-operatively. This result indicated certain intrinsic associations between serum CA125 levels and FDC sarcoma. However, elevated serum CA125 levels have not been observed in other reported FDC sarcomas. Although lymphoma cells do not secrete CA125, investigators have reported serum elevations of CA125 in as many as $40 \%$ of patients with non-Hodgkin's lymphoma, particularly when peritoneal, pleural or pericardial effusions were present (27). Various investigators have proposed including serum CA125 level in prognostic indices for lymphoma (28). The value of elevated CA125 levels for FDC sarcoma diagnosis remains to be determined.

Although the optimal treatment modality of FDC sarcoma has yet to be defined due to the limited number of reported cases, the current therapeutic guidelines refer to treatment modalities used for soft tissue sarcomas of high grade. Treatment principles include radical resection, adjuvant radiation and chemotherapy (2). Radical resection of the tumor is the primary therapy, although the treatment modalities for FDC sarcoma vary widely. FDC sarcoma was previously considered an indolent tumor with low tendency towards recurrence or metastasis. However, findings of studies with larger patient cohorts and longer follow-up have shown that FDC sarcoma is a more aggressive tumor and should be considered an intermediate-grade malignancy. It has been reported that at least $40 \%$ of documented FDC sarcomas have recurred and $25 \%$ have metastasized with a mortality rate of $16.7 \%(2,8)$. Due to this significant recurrent and metastatic potential, it is reasonable that, following radical resection of the localized tumor, recurrence may be prevented by adjuvant radiotherapy or chemotherapy (29-31). However, the role of radiotherapy and chemotherapy in the treatment of this neoplasm has yet to be clearly defined since the value of these adjuvant treatments to effectively improve survival rates remains to be determined $(2,8)$. The present case suggested that FDC sarcoma is effectively treated by surgery and no radiotherapy or chemotherapy after radical excision is required.

In conclusion, extranodal FDC sarcoma is an extremely rare tumor. Due to the scarcity of the identified cases, FDC remains under-recognized and misdiagnosis is common. With the aid of immunohistochemical analysis and the two most reliable FDC markers, CD21 and CD35, the diagnostic accuracy has been significantly improved. Therefore, when FDC sarcoma is suspected histologically, immunohistochemical stains for FDC differentiation should be performed to avoid potential misdiagnosis.

\section{Acknowledgements}

This study was supported by the State Key Basic Research and Development Program of China (973 Program, Grant no. 2009CB521704), the National High-tech Research \& Development Program of China (863 Program, Grant no. 2006AA02A245) and the Zhejiang Provincial Science and Technology Project (Grant no. 2009C13021).

\section{References}

1. Monda L, Warnke $\mathrm{R}$ and Rosai J: A primary lymph node malignancy with features suggestive of dendritic reticulum cell differentiation. A report of 4 cases. Am J Pathol 122: 562-572, 1986.

2. Shia J, Chen W, Tang LH, Carlson DL, Qin J, Guillem JG, Nobrega J, Wong WD and Klimstra DS: Extranodal follicular dendritic cell sarcoma: clinical, pathologic and histogenetic characteristics of an underrecognized disease entity. Virchows Arch 449: 148-158, 2006.

3. Chan JK, Tsang WY, Ng CS, Tang SK, Yu HC and Lee AW: Follicular dendritic cell tumors of the oral cavity. Am J Surg Pathol 18: 148-157, 1994.

4. Youens KE and Waugh MS: Extranodal follicular dendritic cell sarcoma. Arch Pathol Lab Med 132: 1683-1687, 2008.

5. Nayler SJ, Verhaart MJ and Cooper K: Follicular dendritic cell tumour of the tonsil. Histopathology 28: 89-92, 1996.

6. Hollowood K, Stamp G, Zouvani I and Fletcher CD: Extranodal follicular dendritic cell sarcoma of the gastrointestinal tract. Morphologic, immunohistochemical and ultrastructural analysis of two cases. Am J Clin Pathol 103: 90-97, 1995.

7. Perez-Ordonez B, Erlandson RA and Rosai J: Follicular dendritic cell tumor: report of 13 additional cases of a distinctive entity. Am J Surg Pathol 20: 944-955, 1996.

8. Chan JK, Fletcher CD, Nayler SJ and Cooper K: Follicular dendritic cell sarcoma. Clinicopathologic analysis of 17 cases suggesting a malignant potential higher than currently recognized. Cancer 79: 294-313, 1997.

9. Araujo VC, Martins MT, Salmen FS and Araujo NS: Extranodal follicular dendritic cell sarcoma of the palate. Oral Surg Oral Med Oral Pathol Oral Radiol Endod 87: 209-214, 1999.

10. Galati LT, Barnes EL and Myers EN: Dendritic cell sarcoma of the thyroid. Head Neck 21: 273-275, 1999.

11. Choi PC, To KF, Lai FM, Lee TW, Yim AP and Chan JK: Follicular dendritic cell sarcoma of the neck: report of two cases complicated by pulmonary metastases. Cancer 89: 664-672, 2000.

12. Beham-Schmid C, Beham A, Jakse R, Aubock L and Hofler G: Extranodal follicular dendritic cell tumour of the nasopharynx. Virchows Arch 432: 293-298, 1998. 
13. Fonseca R, Tefferi A and Strickler JG: Follicular dendritic cell sarcoma mimicking diffuse large cell lymphoma: a case report. Am J Hematol 55: 148-155, 1997.

14. Schwarz RE, Chu $\mathrm{P}$ and Arber DA: Extranodal follicular dendritic cell tumor of the abdominal wall. J Clin Oncol 17: 2290-2292, 1999.

15. Lee IJ, Kim SC, Kim HS, Bang D, Yang WI, Jung WH and Chi HS: Paraneoplastic pemphigus associated with follicular dendritic cell sarcoma arising from Castleman's tumor. J Am Acad Dermatol 40: 294-297, 1999.

16. Shek TW, Liu CL, Peh WC, Fan ST and Ng IO: Intra-abdominal follicular dendritic cell tumour: a rare tumour in need of recognition. Histopathology 33: 465-470, 1998.

17. Shek TW, Ho FC, Ng IO, Chan AC, Ma L and Srivastava G: Follicular dendritic cell tumor of the liver. Evidence for an Epstein-Barr virus-related clonal proliferation of follicular dendritic cells. Am J Surg Pathol 20: 313-324, 1996.

18. Moriki T, Takahashi T, Wada M, Ueda S, Ichien M, Yamane T and Hara H: Follicular dendritic cell tumor of the mesentery. Pathol Res Pract 193: 629-639, 1997.

19. Fisher C, Magnusson B, Hardarson S and Smith ME: Myxoid variant of follicular dendritic cell sarcoma arising in the breast. Annu Diagn Pathol 3: 92-98, 1999.

20. Pallesen G and Myhre-Jensen O: Immunophenotypic analysis of neoplastic cells in follicular dendritic cell sarcoma. Leukemia 1 549-557, 1987.

21. Desai S, Deshpande RB and Jambhekar N: Follicular dendritic cell tumor of the parapharyngeal region. Head Neck 21: 164-167, 1999.

22. Shah RN, Ozden O, Yeldandi A, Peterson L, Rao S and Laskin WB: Follicular dendritic cell tumor presenting in the lung: a case report. Hum Pathol 32: 745-749, 2001.

23. Chan AC, Chan KW, Chan JK, Au WY, Ho WK and $\mathrm{Ng}$ WM: Development of follicular dendritic cell sarcoma in hyaline- vascular Castleman's disease of the nasopharynx: tracing its evolution by sequential biopsies. Histopathology 38: $510-518,2001$
24. Chiaramonte MF, Lee D, Abruzzo LV, Heyman M and Bass BL: Retroperitoneal follicular dendritic cell sarcoma presenting as secondary amyloidosis. Surgery 130: 109-111, 2001.

25. Chang KC, Jin YT, Chen FF and Su IJ: Follicular dendritic cell sarcoma of the colon mimicking stromal tumour. Histopathology 38: 25-29, 2001.

26. Han JH, Kim SH, Noh SH, Lee YC, Kim HG and Yang WI: Follicular dendritic cell sarcoma presenting as a submucosal tumor of the stomach. Arch Pathol Lab Med 124: 1693-1696, 2000.

27. Bairey O, Blickstein D, Stark P, Prokocimer M, Nativ HM, Kirgner I and Shaklai M: Serum CA 125 as a prognostic factor in non-Hodgkin's lymphoma. Leuk Lymphoma 44: 1733-1738, 2003.

28. Gui W, Wang T, Wang J, Wang L, He J, Yang B, Zhao Z, Zhang $\mathrm{H}$ and Zhang Q: An improved prognostic parameter for non-Hodgkin's lymphoma based on the combination of three serum tumor markers. Int J Biol Markers 23: 207-213, 2008.

29. Fonseca R, Yamakawa $M$, Nakamura $S$, van Heerde $P$, Miettinen M, Shek TW, Myhre Jensen O, Rousselet MC and Tefferi A: Follicular dendritic cell sarcoma and interdigitating reticulum cell sarcoma: a review. Am J Hematol 59: 161-167, 1998.

30. Nakashima T, Kuratomi $Y$, Shiratsuchi $H$, Yamamoto $H$, Yasumatsu R, Yamamoto $\mathrm{T}$ and Komiyama S: Follicular dendritic cell sarcoma of the neck; a case report and literature review. Auris Nasus Larynx 29: 401-403, 2002.

31. Satoh K, Hibi G, Yamamoto Y, Urano M, Kuroda M and Nakamura S: Follicular dendritic cell tumor in the oro-pharyngeal region: report of a case and a review of the literature. Oral Oncol 39: 415-419, 2003. 